Article

\title{
Cuscuta Species Identification Based on the Morphology of Reproductive Organs and Complete Chloroplast Genome Sequences
}

\author{
Inkyu Park ${ }^{+}{ }^{\circ}$, Jun-Ho Song ${ }^{+}{ }^{(}$, Sungyu Yang, Wook Jin Kim, Goya Choi and \\ Byeong Cheol Moon *D
}

Herbal Medicine Resources Research Center, Korea Institute of Oriental Medicine, Naju 58245, Korea; pik6885@kiom.re.kr (I.P.); songjh@kiom.re.kr (J.-H.S.); sgyang81@kiom.re.kr (S.Y.); ukgene@kiom.re.kr (W.J.K.); serparas@kiom.re.kr (G.C.)

* Correspondence: bcmoon@kiom.re.kr; Tel.: +82-61-338-7100

+ These authors contributed equally to this work.

Received: 7 May 2019; Accepted: 1 June 2019; Published: 3 June 2019

check for updates

\begin{abstract}
The genus Cuscuta (Convolvulaceae) comprises well-known parasitic plants. Cuscuta species are scientifically valuable, as their life style causes extensive crop damage. Furthermore, dried seeds of $C$. chinensis are used as a Korean traditional herbal medicine. Despite the importance of Cuscuta species, it is difficult to distinguish these plants by the naked eye. Moreover, plastid sequence information available for Cuscuta species is limited. In this study, we distinguished between $C$. chinensis and C. japonica using morphological characterisation of reproductive organs and molecular characterisation of chloroplast genomes. The differences in morphological characteristics of reproductive organs such as style, stigma, infrastaminal scale, seed shape and testa ornamentation were useful for distinguishing between C. japonica and C. chinensis. Analysis of chloroplast genomes revealed drastic differences in chloroplast genome length and gene order between the two species. Although both species showed numerous gene losses and genomic rearrangements, chloroplast genomes showed highly similar structure within subgenera. Phylogenetic analysis of Cuscuta chloroplast genomes revealed paraphyletic groups within subgenera Monogynella and Grammica, which is consistent with the APG IV system of classification. Our results provide useful information for the taxonomic, phylogenetic and evolutionary analysis of Cuscuta and accurate identification of herbal medicine.
\end{abstract}

Keywords: Cuscuta; parasitic plant; plastid; microscopic analysis; herbal medicine

\section{Introduction}

Cuscuta L. (dodder) is a genus comprising 170-200 species of parasitic vines belonging to the family Convolvulaceae [1,2]. Plants in the genus Cuscuta are clearly distinguishable from those in other Convolvulaceae genera based on the absence of leaves, presence of haustoria and acotyledonous embryo, arrangement of flowers in clusters or short racemes and presence of five-fimbriate scales within the corolla [2]. Cuscuta is nearly cosmopolitan in distribution; however, the majority of the species ( 75\%) are native to North and South America, and other taxa are found only in Asia and Europe [1,2]. Although some dodders (15-20 species) cause economic or ecological damage to crop production worldwide as agricultural, horticultural or exotic pests [3-5], more species are endangered or even threatened, requiring conservation efforts [6]. However, it is very difficult to identify Cuscuta species because of the drastically reduced or almost absent vegetative organs (leaves and stems) and very small floral organs. Therefore, most studies have focused on the microscopic evaluation of 
seed [7], pollen [8], stigma [9] and infrastaminal scales [10] and evolution of these traits of Cuscuta species. These studies focused on only the selected character states and their evolution. However, to date, comprehensive species-based analysis of morphological and molecular characteristics has not been performed.

Chloroplasts play important roles in photosynthesis, carbon fixation and starch and fatty acid biosynthesis [11,12]. Recently, many chloroplast genomes have been sequenced using high-throughput sequencing technology [13]. Chloroplast genome sequences are helpful for species identification, population genetics, molecular marker development and analysis of phylogenetic relationship, diversity and evolution as well as for discriminating authentic herbal medicinal plants from adulterants using limited universal DNA barcodes [13-15]. In general, angiosperm chloroplast genomes exhibit a conserved quadripartite structure with a large single copy (LSC) region, a small single copy (SSC) region and two copies of inverted repeats (IRs) [16]. The chloroplast genome ranges from 100 to $180 \mathrm{~kb}$ in size in higher plants and harbours 110-130 genes, including protein-coding genes and genes encoding ribosomal RNAs (rRNAs) and transfer RNAs (tRNAs) [16]. By contrast, chloroplasts in parasitic plants exhibit reduced genome size, lower gene content and gene loss, as a result of environmental adaptation [17-20]. In the genus Cuscuta, complete chloroplast genomes have been reported for five species, including C. reflexa, C. gronovii, C. exaltata, C. obtusiflora and C. pentagona [19-21]. Chloroplast genomes of these species exhibit gene loss, signatures of selection, genomic rearrangement and differences in genome size, gene number and GC content. Comparison of chloroplast genome sequences of $C$. exaltata, C. obtusiflora and Ipomoea purpurea shows that all $n d h$ genes have been lost in C. exaltata. Despite highly variable nucleotide substitutions, C. obtusiflora has retained the genes involved in photosynthesis and photorespiration, similar to other parasitic plants [17,20]. Chloroplast genome sequence analysis of $C$. reflexa and C. gronovii shows the presence of two inversions in the LSC region and one inversion in the SSC region. Furthermore, C. reflexa and C. gronovii exhibit different degrees of parasitism, with reduction in RNA editing [19]. Although a few complete chloroplast genomes are available in the genus Cuscuta, further investigation is needed for high-resolution phylogenetic analysis as well as Cuscuta species identification because of differences in the life style of different parasitic species, numerous existing species and rapid gene evolution.

In Korean traditional medicine, dried seeds of $C$. chinensis are used as an important herbal medicine, namely, Cuscutae Semen, which is designated as a medicine in the Korean Herbal Pharmacopoeia [22], and is regulated by the Ministry of Food and Drug Safety because of its pharmaceutical properties [23-25]. Only the seeds of $C$. chinensis are considered as authentic Cuscutae Semen in Korea [22]. However, similar Cuscuta species such as C. japonica, C. pentagona and C. australis are also distributed in Korea [26,27]. Since seeds of these species are morphologically highly similar to the naked eye, Cuscutae Semen has been misused and/or mixed with seeds from other Cuscuta species in Korean herbal markets. Thus, accurate identification of Cuscuta species is important for maintaining a uniform pharmacological effect of the herbal medicine.

In this study, we conducted a microscopic analysis of the reproductive organs of $C$. japonica and C. chinensis and sequenced the chloroplast genomes of both species. Results showed differences in the morphological traits of floral organs and seeds as well as in the complete chloroplast genomes of C. japonica and C. chinensis. Comparison of chloroplast genome sequences of $C$. japonica, C. chinensis and related species revealed genomic rearrangements. The genus Cuscuta showed highly variable genome structure and gene content among various species. However, subgenera Grammica and Monogynella exhibited conserved chloroplast genome structure. Our results provide valuable data for the accurate identification of Cuscuta species on the basis of morphological and genomic features and in-depth insight into the evolution of species within the Convolvulaceae. Furthermore, this study will help preserve the quality of Cuscutae Semen as a valuable herbal medicine. 


\section{Results and Discussion}

\subsection{Morphological Characteristics of Reproductive Organs}

Like other parasitic plants [28], Cuscuta species have drastically reduced vegetative organs (stems and leaves) and diverse reproductive organs (flowers and fruits). Thus, morphological characteristics of reproductive organs have been used for the taxonomic and systematic analysis of Cuscuta species. Here, we conducted a microscopic evaluation of the morphology of reproductive organs of $C$. japonica and C. chinensis.

The morphology of reproductive structures, such as style and stigma, of $C$. japonica (Figure 1a) and $C$. chinensis (Figure $1 \mathrm{~b}$ ) was clearly distinct. Flowers of $C$. japonica exhibited one style with cylindrical and ellipsoid stigma (Figure 1a), whereas C. chinensis flowers showed two styles with capitate stigmata (Figure 1b). However, at the cellular level, papillate cells in stigma and ovary, and striate cells in style, were observed in both C. japonica (Figure 1a) and C. chinensis (Figure 1b). Choisy [29] was the first to propose the infrageneric classification of the genus Cuscuta, based on the shape of stigmata. Later, Engelmann [30] used style number and stigma morphology for the classification of three major groups, which have been universally accepted by various authors [31-34] as subgenera: Cuscuta, Grammica and Monogyna (Monogynella). Micromorphological analysis also revealed significant differences between $C$. japonica and $C$. chinensis in the fimbriae of infrastaminal scale (IFS) in flowers. The IFS of $C$. japonica flowers comprised mainly glandular cells (Figure 1c), whereas that of $C$. chinensis flowers comprised secretory cells, called internal laticifers (Figure 1d). Recently, Costea et al. [1] proposed a new classification with four subgenera (Cuscuta, Grammica, Monogynella and Pachystigma) and 18 sections, based on the phylogenetic framework and floral morphology including IFS types. In the present study, we confirmed that IFS type, style number and stigma morphology were useful for the identification of C. japonica (representative of subgenus Monogynella) and C. chinensis (representative of subgenus Grammica). However, there were no major differences in the epidermal cell type of gynoecium (including stigma, style and ovary) between the two species. This high homoplasy of gynoecium cell patterns may have been affected by convergent evolution, like other floral characteristics $[1,9,35,36]$. Seed shape varied from pyriform to oblate in C. japonica (Figure 1e) but was mainly obovoid in C. chinensis (Figure 1f). Moreover, C. japonica seeds showed rugulated (puzzle-like) testa ornamentation (Figure $1 \mathrm{~g}$ ), whereas $C$. chinensis seeds showed reticulate testa ornamentation (Figure 1h). These differences in reproductive traits such as the number of styles, shape of stigma and IFS and ornamentation of testa were consistently observed in all samples collected from different sites and individuals each species. Seed characteristics have been used for distinguishing various subgenera and sections of Cuscuta [7,37]. In this study, seed shape and testa ornamentation clearly separated C. japonica and C. chinensis. Moreover, testa ornamentation showed less variability at the species level, suggesting that seed surface may be a stable characteristic, unchanged according to geographical conditions, for differentiating between $C$. japonica and $C$. chinensis. This comprehensive comparative analysis of reproductive organs of two Cuscuta species revealed that style number, stigma morphology, IFS type, seed shape and testa ornamentation were the most useful and stable characteristics for species identification (Table S1). 

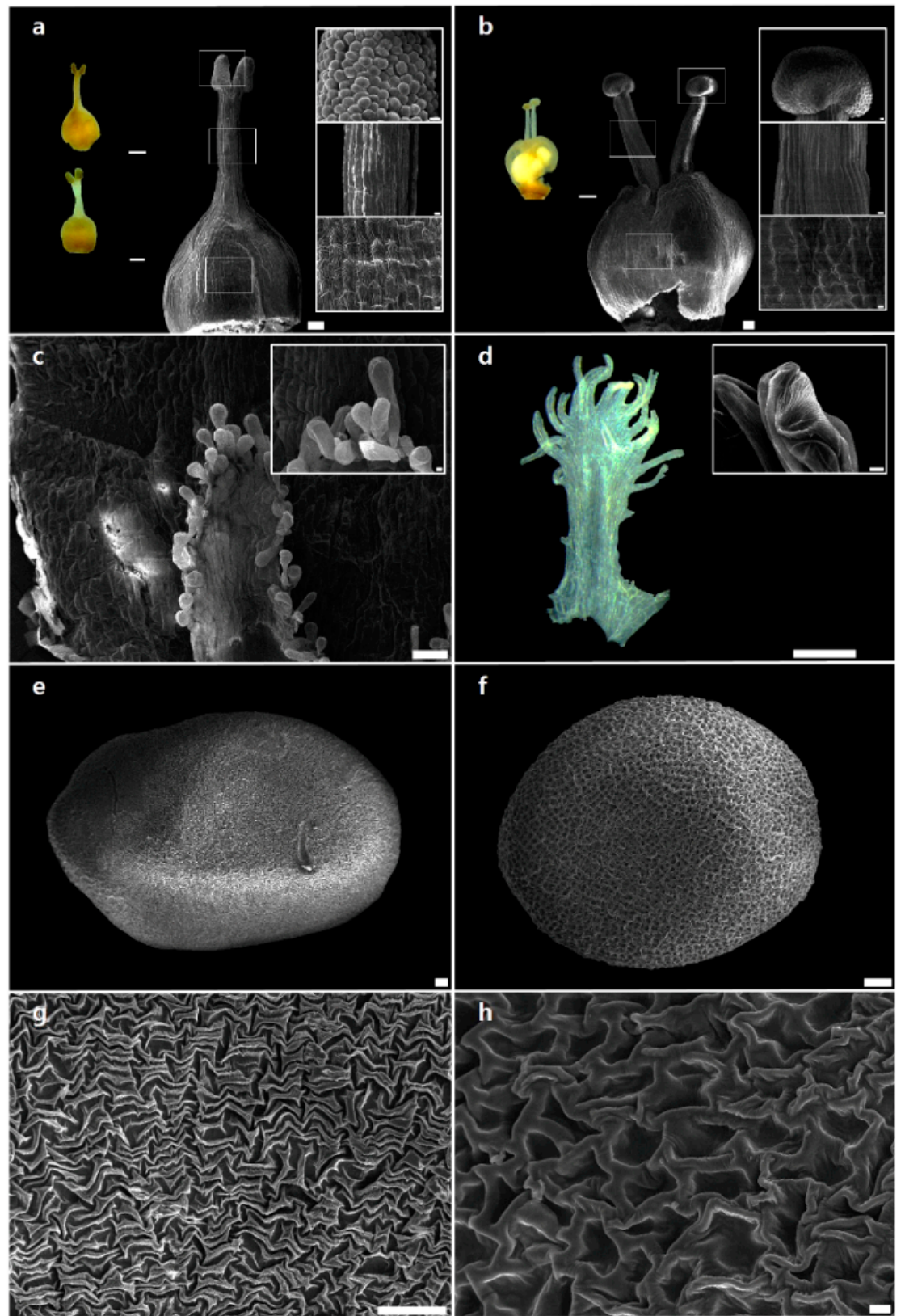

Figure 1. Scanning electron microscope (SEM) and light microscope (LM) micrographs showing the morphology of the major reproductive organs of Cuscuta japonica and C. chinensis. (a) Gynoecium with one style. Small LM micrographs show cylindrical and ellipsoid stigmata (left). SEM micrographs at a higher resolution (right) show cylindrical stigma with papillate cells (top), style with striate cells (middle) and ovary with papillate cells (bottom). (b) Gynoecium with two (equal and unequal) styles. Small LM micrographs show unequal styles (left). SEM micrographs at a higher resolution (right) show capitate stigma with papillate cells (top), style with striate cells (middle) and ovary with papillate cells (bottom). Scale bars: $100 \mu \mathrm{m}(\mathbf{a}, \mathbf{b}) ; 1 \mathrm{~mm}$ (small LM micrographs of a,b); $10 \mu \mathrm{m}$ (small SEM micrographs of $a, b)$. (c) Fimbriae of infrastaminal scale (IFS). Inset shows IFS with glandular trichomes. (d) IFS. Inset shows IFS with secretory cells (internal laticifers). Scale bars: $100 \mu \mathrm{m}$ (c,d); $10 \mu \mathrm{m}$ (small SEM micrographs of c,d). (e) Pyriform to oblate seed shape. (f) Globose to obovoid seed shape. (g) Rugulate (puzzle-like) testa ornamentation. (h) Reticulate (net-like) testa ornamentation. Scale bars: $100 \mu \mathrm{m}$ $(\mathbf{e}-\mathbf{g}) ; 10 \mu \mathrm{m}(\mathbf{h}) .(\mathbf{a}, \mathbf{c}, \mathbf{e}, \mathbf{g})$ C. japonica. $(\mathbf{b}, \mathbf{d}, \mathbf{f}, \mathbf{h})$ C. chinensis. 


\subsection{Chloroplast Genome Features of C. japonica and C. chinensis}

To distinguish between $C$. japonica and $C$. chinensis on the basis of chloroplast genome features, we sequenced the chloroplast genomes of both species (Table S2). Paired-end reads of 2.0 and $2.1 \mathrm{~Gb}$ were obtained from $C$. japonica and C. chinensis, respectively, with trimmed reads of $1.5 \mathrm{~Gb}$ in both species. Complete chloroplast genome sequences of C. japonica and C. chinensis are 121,037 and 86,927 bp in length, with approximately $69 \times$ and $354 \times$ coverage, respectively. Both chloroplast genomes showed a quadripartite structure. The length of the LSC region is 79,517 bp and 50,572 bp in C. japonica and C. chinensis, respectively, and that of the SSC region is $8412 \mathrm{bp}$ and $7121 \mathrm{bp}$, respectively. Inverted repeat (IR) regions (IRa and IRb) are 16,554 bp and 14,617 bp in C. japonica and C. chinensis, respectively. The complete chloroplast genomes were validated using PCR-based sequencing using sequence-specific primers (Table S3). PCR products of the four junctions (LSC/IRa, IRa/SSC, SSC/IRb, IRb/LSC) were analysed by comparison with the complete chloroplast genome sequences (Table S4). We also validated to read mapping on complete chloroplast genomes (Figure S1). The complete chloroplast genomes were of high quality in both species (Figure 2, Table 1). The GC content of $C$. japonica and C. chinensis was $38.3 \%$ and $37.6 \%$, respectively (Table 1). In general, the GC content of IRs was higher than that of LSC and SSC regions in both chloroplast genomes. Gene content and gene order were substantially different between the two Cuscuta chloroplast genomes; the chloroplast genome of $C$. japonica harboured 96 unique genes, including 65 protein-coding genes, four rRNA genes and 29 tRNA genes (Table S5), whereas that of $C$. chinensis contained 85 unique genes, including 58 protein-coding genes, four rRNA genes and 24 tRNA genes (Table 1, Table S6). Both chloroplast genomes showed extensive gene loss within the nadh gene family. Additionally, the C. chinensis chloroplast genome exhibited the loss of eight tRNA genes and greater gene loss in the RNA polymerase gene family than the $C$. japonica chloroplast genome (Table S7). The number of intron-containing genes was nine in C. japonica and four in C. chinensis (Table S8). Codon usage and anticodon recognition patterns of the chloroplast genomes of both Cuscuta species were also analysed. Chloroplast genomes contained 19,180 codons in C. japonica and 16,729 codons in C. chinensis. Codons for leucine and serine were the most abundant in both chloroplast genomes (Figure S2). Value of the relative synonymous codon usage (RSCU) was greater than one for arginine, leucine and serine codons, as expected (Figure S3). The RSCU values represented synonymous codon bias with a high proportion of A or T in the third position, similar to other chloroplast genomes [38].
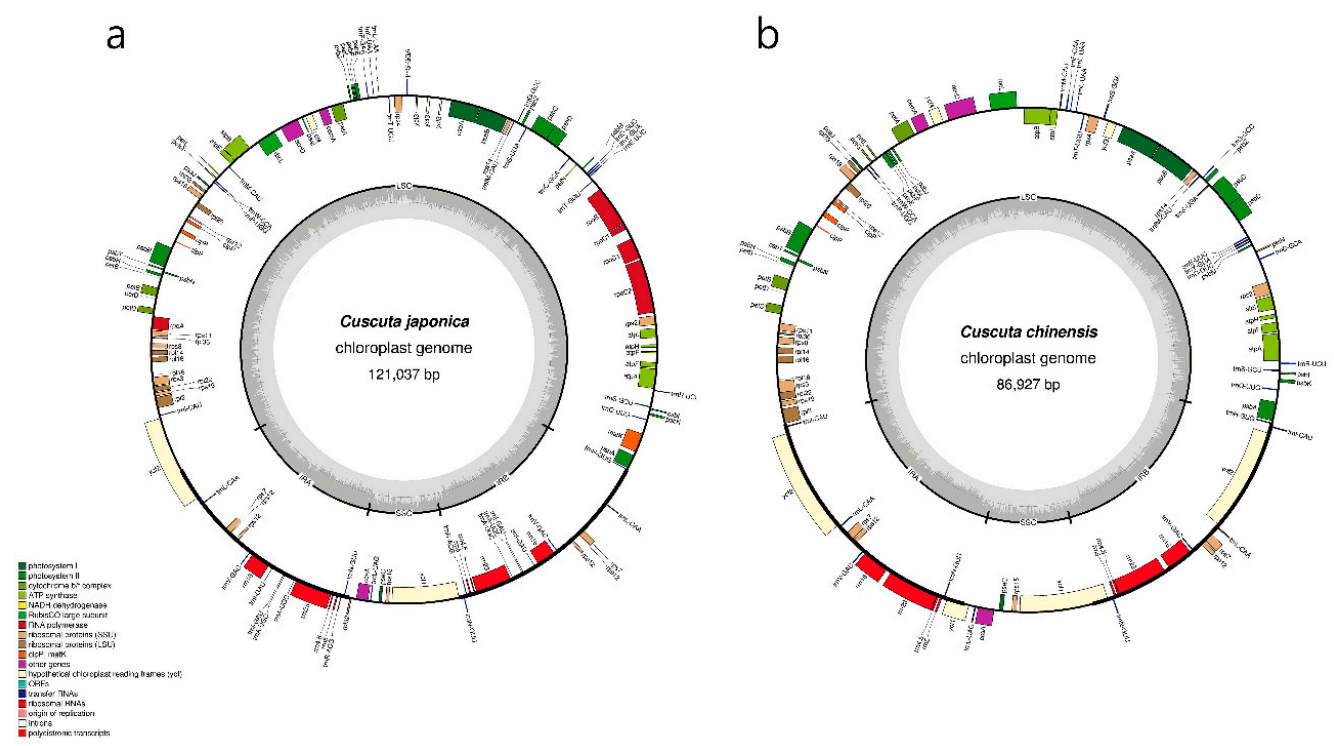

Figure 2. Chloroplast genome maps of C. japonica and C. chinensis. (a) C. japonica. (b) C. chinensis. Genes drawn inside the circle are transcribed clockwise, and those outside the circle are transcribed counterclockwise. Dark grey shading in the inner circle represents the GC content. 
Table 1. Characterisation of the chloroplast genomes of seven Cuscuta species.

\begin{tabular}{cccccccc}
\hline & $\begin{array}{c}\text { C. } \\
\text { japonica }\end{array}$ & C. reflexa & $\begin{array}{c}\text { C. } \\
\text { exaltata }\end{array}$ & $\begin{array}{c}\text { C. } \\
\text { chinensis }\end{array}$ & $\begin{array}{c}\text { C. } \\
\text { gronovii }\end{array}$ & $\begin{array}{c}\text { C. } \\
\text { pentagona }\end{array}$ & $\begin{array}{c}\text { C. } \\
\text { obtusiflora }\end{array}$ \\
\hline $\begin{array}{c}\text { GenBank accession } \\
\text { number }\end{array}$ & This study & NC009766 & NC009963 & This study & NC009765 & NC039759 & NC009949 \\
\hline $\begin{array}{c}\text { Chloroplast genome size } \\
\text { (bp) }\end{array}$ & 121,037 & 121,521 & 125,373 & 86,927 & 86,744 & 86,380 & 85,280 \\
\hline $\begin{array}{c}\text { Large single copy (LSC) } \\
\text { region (bp) }\end{array}$ & 79,517 & 79,468 & 82,721 & 50,572 & 50,973 & 50,958 & 50,201 \\
\hline $\begin{array}{c}\text { Inverted repeat (IR) } \\
\text { region (bp) }\end{array}$ & 16,554 & 16,741 & 16,701 & 14,617 & 14,354 & 14,200 & 14,131 \\
\hline $\begin{array}{c}\text { Small single copy (SSC) } \\
\text { region (bp) }\end{array}$ & 8412 & 8571 & 9250 & 7121 & 7063 & 7022 & 6817 \\
\hline Total number of genes & 96 & 98 & 98 & 85 & 86 & 85 & 86 \\
\hline $\begin{array}{c}\text { Number of } \\
\text { protein-coding genes }\end{array}$ & 65 & 65 & 65 & 58 & 58 & 57 & 58 \\
\hline Number of rRNA genes & 4 & 4 & 4 & 4 & 4 & 4 & 4 \\
\hline Number of tRNA genes & 27 & 29 & 29 & 23 & 24 & 24 & 24 \\
\hline GC content (\%) & 38.3 & 38.2 & 38.1 & 37.6 & 37.7 & 37.9 & 37.8 \\
\hline LSC (\%) & 36 & 36.1 & 35.8 & 35.9 & 35.8 & 36 & 35.9 \\
\hline IR (\%) & 45.7 & 45.7 & 45.6 & 42.8 & 43.1 & 43.2 & 43.2 \\
\hline SSC (\%) & 30.5 & 30.8 & 31 & 28.9 & 29.5 & 29.6 & 29.8 \\
\hline
\end{tabular}

Chloroplast genomes of $C$. japonica and C. chinensis were compared with those of related Cuscuta species. Chloroplast genome features of $C$. japonica and $C$. chinensis were consistent with those of other species in the respective subgenera; the chloroplast genome of $C$. japonica was similar to that of $C$. reflexa and C. exaltata in subgenus Monogynella, whereas the chloroplast genome of $C$. chinensis was consistent with that of species in subgenus Grammica (Table 1). Two subgenera, Monogynella and Grammica, showed dramatically different genome length, gene content, GC content patterns of chloroplast genomes. Compared with the closest species, Ipomoea nil, chloroplast genomes of C. japonica and C. chinensis showed a loss of 17 and 28 genes, respectively (Table S7). This gene loss affected the chloroplast genome length $[17,19,39]$. Genes encoding NAD(P)H-dehydrogenase enzymes were absent in the chloroplast genomes of both species. All $n d h$ genes have been lost in both $C$. japonica and C. chinensis, similar to other Cuscuta species $[19,20]$. The loss of $n d h$ genes has been reported in other parasitic plants as well as in other land plants [40-42]. The $n d h$ genes were first lost during the evolution of parasitism because of relaxed selection pressure $[17,19,20]$. Because the loss of $n d h$ genes reduced the photosynthetic capacity of plants, Cuscuta species evolved to obtain nutrients from host plants [17].

We also surveyed simple sequence repeats (SSRs, also known as microsatellites) and tandem repeats in chloroplast genomes of Cuscuta species. SSRs are abundant in genomes, and have been widely used in phylogenetic analysis and population genetics [43,44]. A total of 141 and 94 SSRs were detected in C. japonica and C. chinensis chloroplast genomes, respectively (Figure S4). The number of SSRs per unit length was higher in single copy regions (LSC and SSC) than in IR regions in chloroplast genomes of both species. SSRs in intergenic spacer (IGS) regions and exons were mononucleotide and dinucleotide in chloroplast genomes of both species (Figure S4). Tandem repeats originate from genomic rearrangements and gene duplication events [45]. We detected 13 and five tandem repeats in chloroplast genomes of $C$. japonica and C. chinensis, respectively (Table S9). Numerous tandem repeats (>100 bp) were detected in the C. japonica chloroplast genome. These repeats will serve as useful resources for marker development for species identification. 


\subsection{Dynamic Chloroplast Genome Structure of Cuscuta}

To determine the variation in chloroplast genome structure in the genus Cuscuta, we compared chloroplast genomes of seven Cuscuta species (Figure 3). Rearrangements were detected in four regions among the seven species, and chloroplast genome sizes and gene contents were variable. However, gene content, gene order and genome size were similar at the subgenus level. Two inversions 11.4 and $1.1 \mathrm{~kb}$ in length, were detected. The $11.4 \mathrm{~kb}$ inversion was present within the LSC region and contained 13 genes ( $p s b E, p s b F, p s b L, p s b J$, petA, cemA, $y c f 4, p s a I, a c c D, r b c L, a t p B$, atpE and trnM-CUA), while the $1.1 \mathrm{~kb}$ inversion was present in the SSC region and contained two genes ( $\operatorname{cs} A$ and $\operatorname{trnL} L-U A G$ ); these inversions separated Cuscuta species at the subgenus level. Compared with five Cuscuta species, chloroplast genomes of $C$. japonica and $C$. reflexa harboured a $2.3 \mathrm{~kb}$ inversion (containing trnT-GGU, trnE-UUC, trnY-GUA, trnD-GUC, $p s b M$, pet N and trnC-GCA) within the LSC region. The chloroplast genome of $C$. obtusiflora harboured a species-specific inversion in the SSC region comprising the trnL-ycf1 gene. Another inversion, $7.1 \mathrm{~kb}$ in length, comprised $t r n L-U A G, c c s A, p s a C, r p s 15$ and $y c f 1$ genes in C. obtusiflora. Chloroplast genomes in the genus Cuscuta exhibited structural vitiations, contained well-conserved syntenic regions which was divided in two subgenera (Figure S5). Single copy regions formed seven well-conserved local collinear blocks among the seven Cuscuta species, and IR regions were not detected in syntenic regions (Figure S5). Other Cuscuta, C. reflex and C. gronovii, have structural variation, which is consistent with our results [19]. Large-scale rearrangements were identified by comparative analysis of seven Cuscuta chloroplast genomes. We suggest that genomic rearrangements of $p s b E-t r n M$ in the LSC region and $\operatorname{css} A-\operatorname{trn} L$ in the SSC region arose before divided to subgenera in Cuscuta.

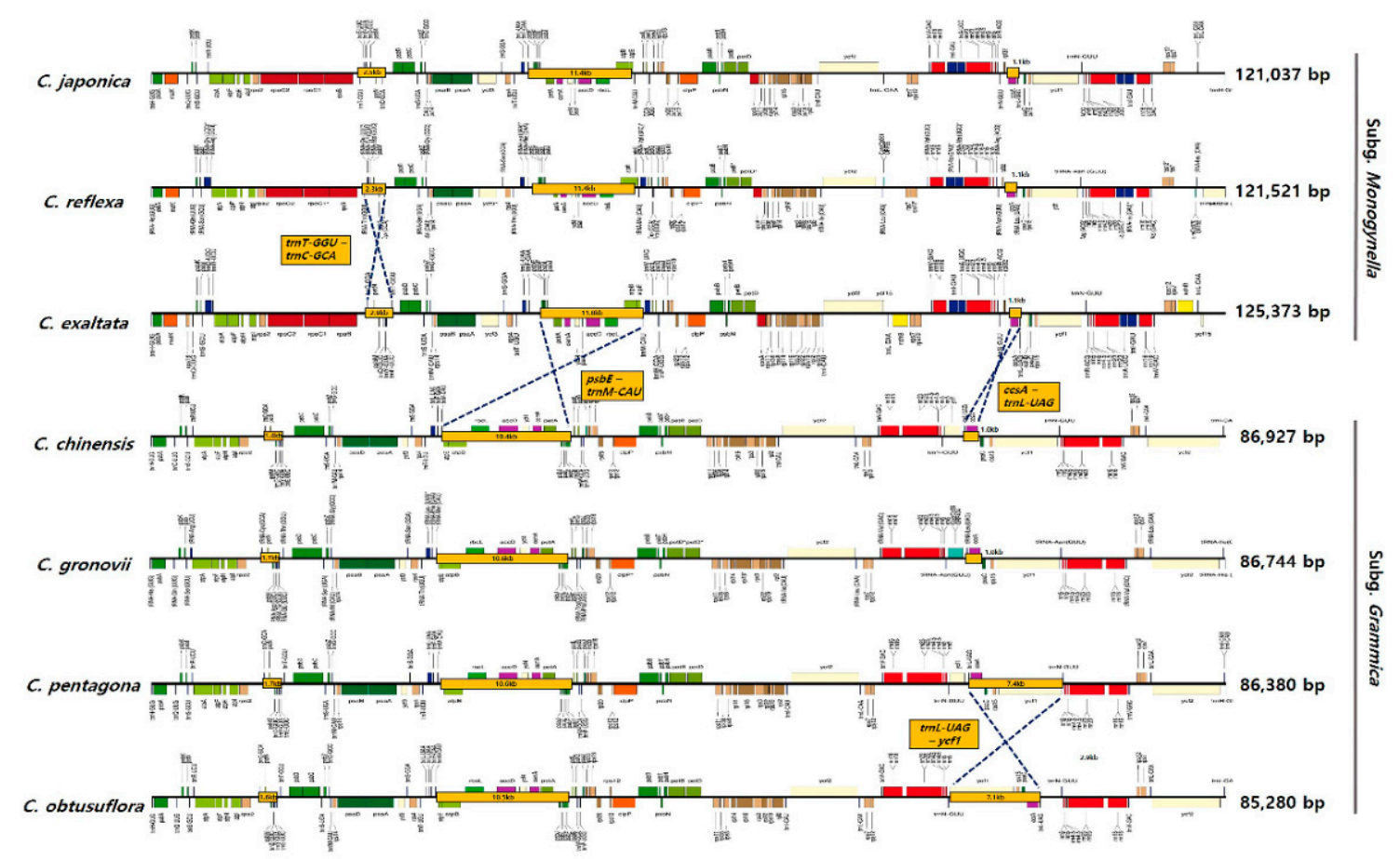

Figure 3. Linear chloroplast genome maps of seven Cuscuta species. Linear maps were drawn using OGDRAW. Yellow boxes indicate inversions. Chloroplast genomes of C. reflexa, C. exaltata, C. gronovii, C. pentagona and C. obtusiflora were downloaded from GenBank. 
Next, we compared sequences of the junctions between single copy regions and IR regions in the seven Cuscuta species. The length of IR regions was lower in the seven species than in other angiosperms. Two patterns of contraction of the IR regions separated the seven species at the subgenus level (Figure S6). In chloroplast genomes of C. japonica, C. reflexa and C. exaltata (subgenus Monogynella), the IR/SSC border extended into $y c f 2$, resulting in a pseudogene in all three chloroplast genomes, with pseudogenisation of ycf15 in IRa. By contrast, C. chinensis, C. gronovii, C. pentagona and C. obtusiflora (subgenus Grammica) harboured rpl2 in the LSC region. The ycf1 gene was located in the SSC/IRb border region in all Cuscuta species, except $C$. exaltata. In C. obtusiflora, inversion was detected in the SSC region. The IR contraction was considerably distinct between Monogynella and Grammica. Nonetheless, similar patterns were observed between the two subgenera. The IR regions are more highly conserved than single copy regions (LSC and SSC) because of copy correction by gene conversion in IR regions in other angiosperms chloroplast genomes [46]. The contraction and expansion of IR regions has led to variation in chloroplast genome length, which is a crucial criterion for evolution $[47,48]$. This suggests that IRs in Cuscuta plastid genomes underwent more contraction than those in chloroplast genomes of other angiosperms, indicating an independent evolutionary process in response to the environment [49]. To identify genetic variation, we analysed the non-synonymous to synonymous substitution ratio $(\mathrm{Ka} / \mathrm{Ks})$ using chloroplast genes conserved among $C$. japonica, C. chinensis and Ipomoea nil. Results showed no positive selection (Figure S7). Most genes showed a high Ka/Ks ratio in C. chinensis. However, in C. japonica, values of Ks were lower than those in C. chinensis. It is possible that chloroplast genes in C. chinensis exhibit more diversity than those in C. japonica; however, genetic variability in C. chinensis is more stable than that in $C$. japonica. This suggests that chloroplast genes in C. chinensis are no longer under selection pressure from the environment and/or have obtained a stable host plant.

\subsection{Phylogenetic Relationship among Cuscuta Species}

Chloroplast genomes have been successfully used in numerous phylogenetic studies of angiosperms because of several advantages such as high accuracy and resolution [13,50]. In this study, we determined the phylogenetic relationship of $C$. japonica and $C$. chinensis with other species within Convolvulaceae using chloroplast genome sequences. A total of 50 conserved protein-coding sequences in 18 chloroplast genomes were aligned over a length of 40,764 bp. A phylogenetic tree was constructed using the maximum likelihood (ML) method. Most nodes showed bootstrap (BS) values of 100\% and Bayesian Inference (BI) posterior probabilities (PP) of 1.0, except the node of Ipomoea species (Figure 4). Two Cuscuta subgenera, Grammica and Monogynella, formed monophyletic groups within Ipomoea. C. exaltata formed a paraphyletic group with two Cuscuta species, C. japonica and C. reflexa. C. chinensis showed a distinct phylogenetic relationship with the other three Cuscuta species within subgenus Grammica. The reconstructed phylogenetic tree is consistent with previous studies, according to the APG IV system of plant classification [51,52]. We first represent a reconstructed phylogenetic tree in two Cuscuta subgenera based on chloroplast protein-coding sequences. The phylogenetic relationship between the two Cuscuta subgenera, Grammica and Monogynella, was strongly supported by high BS and PP values. Moreover, the Cuscuta clade comprising subgenera Grammica and Monogynella is consistent with morphological and micromorphological traits, such as style number, IFS [1] and testa ornamentation [7]. Further studies involving sampling of all four subgenera of Cuscuta [1] and trait analysis are required to enhance our understanding of the evolutionary trends and phylogenetic implication of the reproductive traits within Convolvulaceae. 


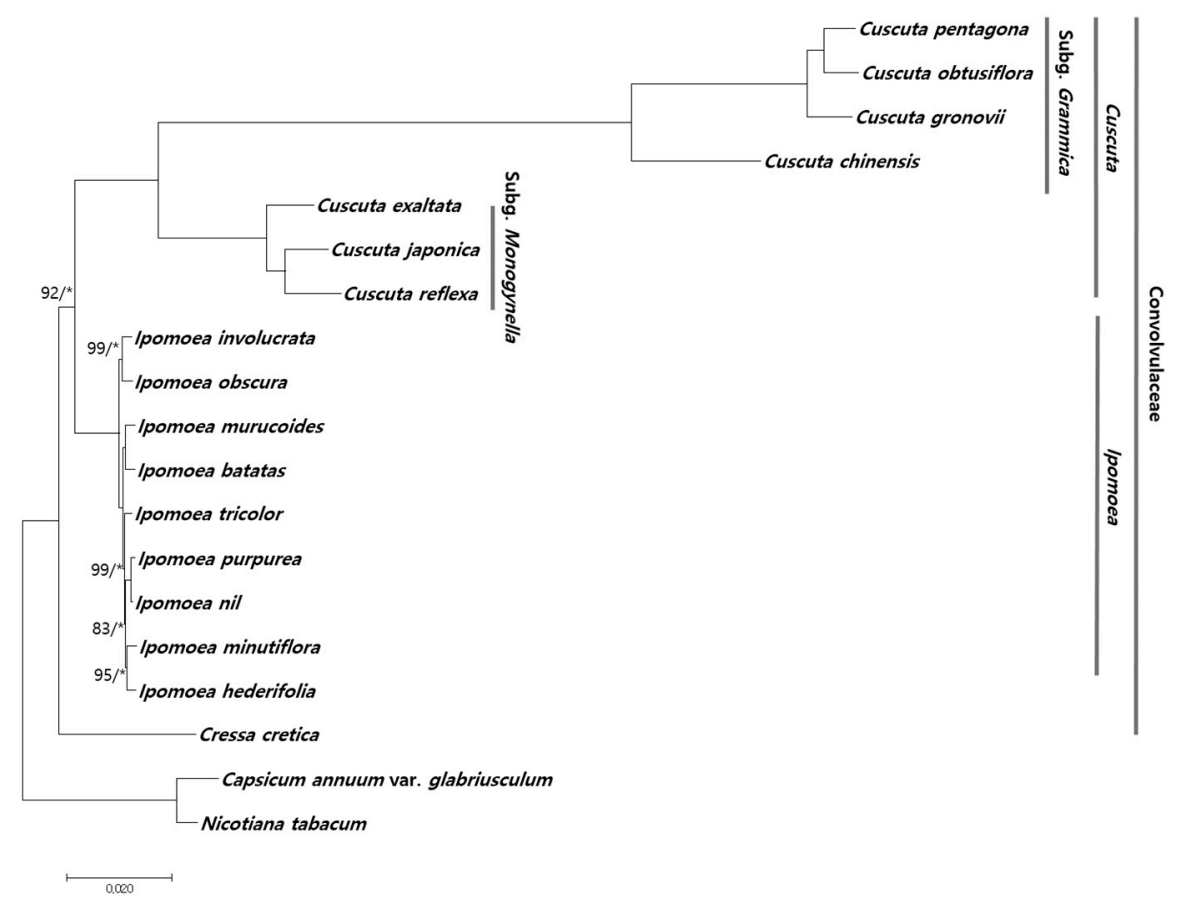

Figure 4. Phylogenetic analysis of Cuscuta and Ipomoea species. The phylogenetic tree was constructed with the maximum likelihood (ML) method and Bayesian Inference (BI) using 50 conserved protein-coding sequences from seven Cuscuta species, nine Ipomoea species and Cressa cretica within the family Convolvulaceae. Capsicum annuum var. glabriusculum and Nicotiana tabacum were used as outgroups. ML topology is shown with bootstrap (BS) values and Bayesian Inference (BI) posterior probability $(\mathrm{PP})$ values at each node. $\mathrm{BS}=100 \%$ and $\mathrm{PP}=1.0$ are not marked. ${ }^{*}$ was shown $1.0 \mathrm{PP}$ values.

\section{Materials and Methods}

\subsection{Plant Material}

Plant material used in this study was collected from natural populations over 3 years (2014-2016). To confirm the consistency of morphological and micromorphological characteristics, at least two sites were compared for each species (C. japonica: six sites, six individuals; $C$. chinensis: two sites, four individuals). Representative fresh vines of $C$. japonica $\left(36^{\circ} 58^{\prime} 34.5^{\prime \prime} \mathrm{N}\right.$ and $128^{\circ} 56^{\prime} 47.5^{\prime \prime} \mathrm{E}$ ) and $C$. chinensis $\left(33^{\circ} 24^{\prime} 29.9^{\prime \prime} \mathrm{N}\right.$ and $\left.126^{\circ} 15^{\prime} 09.8^{\prime \prime} \mathrm{E}\right)$ were used for chloroplast genome sequencing. These samples were assigned identification numbers, and voucher specimens were deposited in the Korean Herbarium of Standard Herbal Resources (Index Herbarium code KIOM) at the Korea Institute of Oriental Medicine (KIOM). Plant samples used for morphological, micromorphological and chloroplast genome sequence analysis are listed in Table S10.

\subsection{Microscopic Analysis}

For reproductive morphological observations, flowers and seeds were examined using a stereomicroscope (Olympus SZX16; Tokyo, Japan) in order to check the fully mature organs. For scanning electron microscopic observations, the dried materials from voucher specimens were rehydrated overnight using the wetting agent Agepon ${ }^{\circledR}$ (Agfa Gevaert; Leverkusen, Germany) and distilled water $(1: 200)$ at $37^{\circ} \mathrm{C}$ The rehydrated materials were dehydrated in a graded ethanol series, and dried in an automated critical point drier (Leica EM CPD 300; Vienna, Austria). The dried materials were fixed on aluminum stubs with double-adhesive carbon tape. The stubs were then coated with gold $(\mathrm{Au})$ using an ion-sputtering device (Cressington Scientific Instruments 208HR; Watford, UK). The prepared floral organs and seeds were observed using a low voltage field emission scanning 
electron microscope (JEOL JSM-7000F; Tokyo, Japan) at an accelerating voltage of $15 \mathrm{kV}$ with a working distance of 9-15 mm [53].

\subsection{Genome Sequencing and Assembly}

DNA was extracted using DNeasy Plant Maxi kit (Qiagen, Valencia, CA, USA), according to the manufacturer's instructions. Illumina short-insert paired-end sequencing libraries were constructed; sequencing was performed using the MiSeq platform (Illumina, San Diego, CA, USA). Chloroplast genome sequences were assembled de novo from low-coverage whole genome sequences. Trimmed paired-end reads (Phred score $\geq 20$ ) were assembled using CLC genome assembler (ver. 4.06 beta; CLC Inc., Rarhus, Denmark) with default parameters. Principal contigs representing chloroplast genome sequences were retrieved using Nucmer [54], and aligned with the reference chloroplast genome sequences of C. gronovii (NC009765) and C. reflexa (NC009766). Gaps in sequences were filled using SOAP de novo gap closer, based on aligned paired-end reads [55]. To validate correct genome assembly, sequences of four chloroplast junctions (LSC/IR, IR/SSC, SSC/IR, IR/LSC) were confirmed by PCR-based sequencing using sequence-specific primers (Table S3). Furthermore, chloroplast reads were mapped onto complete genome sequences using BWA ver. 0.7.25 [56].

\subsection{Genome Annotation and Comparative Analysis}

Annotation of genes in the chloroplast genomes of $C$. japonica and C. chinensis was performed using DOGMA annotation [57]. Codons and gene boundaries were manually corrected using BLAST searches. The tRNAs were confirmed with tRNAscan-SE 1.21 [58]. Circular maps of the two Cuscuta chloroplast genomes were obtained using OGDRAW [59]. GC content and codon usage were analysed using MEGA6 [60]. Local collinear blocks in the chloroplast genome sequences of all seven Cuscuta species investigated in this study (C. japonica, C. exaltata, C. reflexa, C. obtusiflora, C. chinensis, C. pentagona and C. gronovii) were identified using MAUVE V2.3.1 program [61]. Substitution rates Ka and Ks were estimated with PAML using the yn00 program [62].

\subsection{Repeat Analysis}

SSRs in chloroplast genomes of C. japonica and C. chinensis were detected using MISA [63], with minimum number of repeats set to $10,5,4,3,3$ and 3 for mono-, di-, tri-, tetra-, penta- and hexa-nucleotides, respectively. Tandem and palindromic repeats $(\geq 20 \mathrm{bp}$ ) were identified with minimum alignment score $=50$, maximum period size $=500$ and identity of repeats $\geq 90 \%[64,65]$.

\subsection{Phylogenetic Analysis}

A total of 19 chloroplast genomes were used in phylogenetic analysis. Of these, 17 chloroplast genome sequences were downloaded from NCBI (Table S11). Capsicum annuum var. glabriusculum and Nicotiana tabacum were used as outgroups. Molecular phylogenetic trees were constructed using aligned sequences of 50 protein-coding genes with MAFFT [66], and sequences were manually adjusted using Bioedit [67]. The best-fitting model of nucleotide substitutions was determined using the Akaike Information Criterion (AIC) in JModeltest V2.1.10 [68]. The GTR+I+G model was used in both (Table S12). The ML analysis was performed using MEGA6 [60] with 1000 bootstrap replicates. BI analysis was performed in MrBayes 3.2.2 [69] using the Markov Chain Monte Carlo (MCMC) method, with two independent runs (four chains each) for one million generations. Phylogenetic trees were sampled every 1000 generations, with the first $25 \%$ discarded as burn-in. Phylogenetic trees were determined from $50 \%$ majority-rule consensus trees to estimate PP values. 


\section{Conclusions}

Morphological characteristics and chloroplast genome sequences of $C$. japonica and C. chinensis were analysed in this study. The morphology of reproductive organs such as style, stigma, IFS, seed and testa showed considerable differences between C. japonica and C. chinensis. Chloroplast genomes were highly variable with respect to gene content, gene orientation and GC content, and local variations in genome sequence and structure were observed at the subgenus level. Tandem repeats and SSRs were identified with the aim of developing molecular markers for species identification and authentication of herbal medicines. Inversions were detected in LSC and SSC regions at Cuscuta subgenera. Overall, our results will help in the authentication of herbal medicines containing C. japonica and C. chinensis. Analysis of key morphological/micromorphological characteristics and chloroplast genome sequences of C. japonica and C. chinensis provides valuable information for species identification, taxonomic classification and evolutionary analysis of Cuscuta.

Supplementary Materials: Supplementary Materials can be found at http://www.mdpi.com/1422-0067/20/11/ 2726/s1. Figure S1: Distribution of paired-end reads mapped onto the complete chloroplast genomes of two Cuscuta species, C. japonica and C. chinensis. LSC, large single copy region; SSC, small single copy region; IRa, inverted repeat $a ; I R b$, inverted repeat $b$. Figure S2: Frequencies of amino acids in protein-coding regions in chloroplast genomes of $C$. japonica and C. chinensis. Figure S3: Relative synonymous codon usage (RSCU) values of 20 amino acids and stop codon in 65 and 58 protein-coding genes in chloroplast genomes of $C$. japonica and C. chinensis, respectively. Figure S4: Distribution of simple sequence repeats (SSRs) in chloroplast genomes of C. japonica and C. chinensis. (a) Number of SSRs per unit length. (b) Distribution of SSRs in exons, introns and intergenic spacer (IGS) regions. (c) Distribution of different types of SSRs. Figure S5: Comparison of complete chloroplast genomes of seven Cuscuta species using the MAUVE algorithm. Local collinear blocks coloured in this figure indicate syntenic regions, while histograms within each block represent the degree of sequence similarity. Figure S6: Comparison of the position of large single copy (LSC), inverted repeat (IR) and small single copy (SSC) junctions among chloroplast genomes of seven Cuscuta species. Figure S7: Comparison of non-synonymous to synonymous substitution ratios $(\mathrm{Ka} / \mathrm{Ks})$ of 50 conserved protein-coding genes among the chloroplast genomes of C. chinensis, C. japonica and Ipomoea nil. (a) Comparison between Ipomoea nil and C. chinensis. (b) Comparison between I. nil and C. japonica. Blue and orange bars indicate $\mathrm{Ka}$ and $\mathrm{Ks}$ values, respectively, while grey bars indicate $\mathrm{Ka} / \mathrm{Ks}$ ratios. Genes with $\mathrm{Ka}$ or $\mathrm{Ks}=0$ are not shown. Table S1: Morphological and micromorphological characteristics of reproductive organs of Cuscuta japonica and Cuscuta chinensis. Table S2: Raw read and assembly information of two Cuscuta chloroplast genomes. Table S3: Primers used for PCR-based sequence validation of $C$. japonica and C. chinensis chloroplast junctions. Table S4: Results of PCR-based sequencing of chloroplast junctions. Table S5: Genes present in the chloroplast genome of C. japonica. Table S6: Genes present in the chloroplast genome of $C$. chinensis. Table S7: Genes lost from the chloroplast genomes of C. japonica and C. chinensis. Table S8: Lengths of exons and introns of genes in chloroplast genomes of C. japonica and C. chinensis. Table S9: Tandem repeats detected in C. japonica and C. chinensis chloroplast genomes. Table S10: List of C. japonica and C. chinensis specimens examined in this study. Table S11: Accession numbers of chloroplast genomes used for phylogenetic analysis. Table S12: Best-fitting substitution models selection using jModelTest.

Author Contributions: Experimental design, I.P and J.-H.S.; collection and identification of plant material, J.-H.S., S.Y. and G.C.; experiment execution, W.J.K.; genome analysis, I.P.; microscopic analysis, J.-H.S.; manuscript draft preparation, I.P. and J.-H.S.; manuscript review, B.C.M. All authors contributed to the experiments and approved the final manuscript.

Funding: This work was supported by a grant on the Applicational Development of Standardized Herbal Resources (KSN1911420) from the Korea Institute of Oriental Medicine (KIOM), Republic of Korea.

Conflicts of Interest: The authors declare no conflicts of interest.

\section{References}

1. Costea, M.; García, M.A.; Stefanović, S. A phylogenetically based infrageneric classification of the parasitic plant genus Cuscuta (dodders, Convolvulaceae). Syst. Bot. 2015, 40, 269-285. [CrossRef]

2. Fang, R.-C.; Musselman, L.J.; Plitmann, U. Cuscuta Linnaeus. In Flora of China, Gentianaceae Through Boraginaceae; Wu, Z.Y., Raven, P.H., Eds.; Science Press: Beijing, China; Missouri Botanical Garden Press: St. Louis, MO, USA, 1995; Volume 16, pp. 322-325.

3. Dawson, J.H.; Musselman, L.J.; Wolswinkel, P.; Dörr, I. Biology and control of Cuscuta. Rev. Weed Sci. 1994, 6, 265-317. 
4. Costea, M.; Tardif, F.J. The biology of Canadian weeds. 133. Cuscuta campestris Yuncker, C. gronovii Willd. ex Schult., C. umbrosa Beyr. ex Hook., C. epithymum (L.) L. and C. epilinum Weihe. Can. J. Plant Sci. 2006, 86, 293-316. [CrossRef]

5. Hwang, S.; Kil, J.; Lee, C.-W.; Kim, Y. Distribution and host plants of parasitic weed Cuscuta pentagona Engelm. Hangug Jawon Sigmul Haghoeji 2013, 26, 289-302. [CrossRef]

6. Costea, M.; Stefanović, S. Cuscuta jepsonii (Convolvulaceae): An invasive weed or an extinct endemic? Am. J. Bot. 2009, 96, 1744-1750. [CrossRef] [PubMed]

7. Kim, C.; Chung, Y.; Oh, S.M. Taxonomic evaluation of selected Cuscuta species (Cuscutaceae) based on seed morphology. Kor. J. Weed Sci. 2000, 20, 255-263.

8. Welsh, M.; Stefanović, S.; Costea, M. Pollen evolution and its taxonomic significance in Cuscuta (dodders, Convolvulaceae). Plant Syst. Evol. 2010, 285, 83-101. [CrossRef]

9. Wright, M.A.; Welsh, M.; Costea, M. Diversity and evolution of the gynoecium in Cuscuta (dodders, Convolvulaceae) in relation to their reproductive biology: Two styles are better than one. Plant Syst. Evol. 2011, 296, 51-76. [CrossRef]

10. Riviere, S.; Clayson, C.; Dockstader, K.; Wright, M.A.; Costea, M. To attract or to repel? Diversity, evolution and role of the "most peculiar organ" in the Cuscuta flower (dodder, Convolvulaceae)—-the infrastaminal scales. Plant Syst. Evol. 2013, 299, 529-552. [CrossRef]

11. Jansen, R.K.; Ruhlman, T.A. Plastid genomes of seed plants. In Genomics of Chloroplasts and Mitochondria; Springer: Dordrecht, The Netherlands, 2012; pp. 103-126.

12. Daniell, H.; Lin, C.S.; Yu, M.; Chang, W.J. Chloroplast genomes: Diversity, evolution, and applications in genetic engineering. Genome Biol. 2016, 17, 134. [CrossRef]

13. Jansen, R.K.; Cai, Z.; Raubeson, L.A.; Daniell, H.; Depamphilis, C.W.; Leebens-Mack, J.; Muller, K.F.; Guisinger-Bellian, M.; Haberle, R.C.; Hansen, A.K.; et al. Analysis of 81 genes from 64 plastid genomes resolves relationships in angiosperms and identifies genome-scale evolutionary patterns. Proc. Natl. Acad. Sci. USA 2007, 104, 19369-19374. [CrossRef] [PubMed]

14. Park, I.; Yang, S.; Kim, W.J.; Noh, P.; Lee, H.O.; Moon, B.C. The complete chloroplast genomes of six Ipomoea species and indel marker development for the discrimination of authentic Pharbitidis Semen (seeds of $I$. nil or I. purpurea). Front. Plant Sci. 2018, 9, 965. [CrossRef] [PubMed]

15. Dong, W.; Liu, J.; Yu, J.; Wang, L.; Zhou, S. Highly variable chloroplast markers for evaluating plant phylogeny at low taxonomic levels and for DNA barcoding. PLoS ONE 2012, 7, e35071. [CrossRef]

16. Wicke, S.; Schneeweiss, G.M.; de Pamphilis, C.W.; Muller, K.F.; Quandt, D. The evolution of the plastid chromosome in land plants: Gene content, gene order, gene function. Plant Mol. Biol. 2011, 76, $273-297$. [CrossRef]

17. Frailey, D.C.; Chaluvadi, S.R.; Vaughn, J.N.; Coatney, C.G.; Bennetzen, J.L. Gene loss and genome rearrangement in the plastids of five hemiparasites in the family Orobanchaceae. BMC Plant Biol. 2018, 18, 30. [CrossRef] [PubMed]

18. Li, Y.; Zhou, J.G.; Chen, X.L.; Cui, Y.X.; Xu, Z.C.; Li, Y.H.; Song, J.Y.; Duan, B.Z.; Yao, H. Gene losses and partial deletion of small single-copy regions of the chloroplast genomes of two hemiparasitic Taxillus species. Sci. Rep. 2017, 7, 12834. [CrossRef] [PubMed]

19. Funk, H.T.; Berg, S.; Krupinska, K.; Maier, U.G.; Krause, K. Complete DNA sequences of the plastid genomes of two parasitic flowering plant species, Cuscuta reflexa and Cuscuta gronovii. BMC Plant Biol. 2007, 7, 45. [CrossRef]

20. McNeal, J.R.; Kuehl, J.V.; Boore, J.L.; de Pamphilis, C.W. Complete plastid genome sequences suggest strong selection for retention of photosynthetic genes in the parasitic plant genus Cuscuta. BMC Plant Biol. 2007, 7, 57. [CrossRef]

21. Park, I.; Yang, S.; Kim, W.J.; Noh, P.; Lee, H.O.; Moon, B.C. The complete chloroplast genome of Cuscuta pentagona Engelm. Mitochondrial DNA B Resour. 2018, 3, 523-524. [CrossRef]

22. Korea Institute of Oriental Medicine (KIOM). Defining Dictionary for Medicinal Herbs. 2019. Available online: http://boncho.kiom.re.kr/codex/ (accessed on 1 March 2019).

23. Kim, E.-Y.; Kim, E.K.; Lee, H.-S.; Sohn, Y.; Soh, Y.; Jung, H.-S.; Shon, N.-W. Protective effects of Cuscutae semen against dimethylnitrosamine-induced acute liver injury in Sprague-Dawley rats. Biol. Pharm. Bull. 2007, 30, 1427-1431. [CrossRef] 
24. Kang, S.Y.; Jung, H.W.; Lee, M.-Y.; Lee, H.W.; Chae, S.W.; Park, Y.-K. Effect of the semen extract of Cuscuta chinensis on inflammatory responses in LPS-stimulated BV-2 microglia. Chin. J. Nat. Med. 2014, 12, 573-581. [PubMed]

25. Liao, J.-C.; Chang, W.-T.; Lee, M.-S.; Chiu, Y.-J.; Chao, W.-K.; Lin, Y.-C.; Lin, M.-K.; Peng, W.-H. Antinociceptive and anti-inflammatory activities of Cuscuta chinensis seeds in mice. Am. J. Chin. Med. 2014, 42, $223-242$. [CrossRef]

26. Choi, B.H.; Cuscuta, L. The Genera of Vascular Plants of Korea; Flora of Korean Editorial Committee, Ed.; Academic Publishing Co.: Seoul, Korea, 2007; pp. 793-794.

27. Park, S.H. New Illustrations and Photographs of Naturalized Plants of Korea; Ilchokak: Seoul, Korea, 2009.

28. Kuijt, J. The Biology of Parasitic Flowering Plants; University of California Press: Berkeley, CA, USA, 1969.

29. Choisy, J.D. De Convolvulaceis dissertatio tertia, complectens Cuscutarum hucusque cog nitarum methodicam enumerationem et descriptionem, necnon et brevem gallicam de Cuscutis praefationem. Mem. Soc. Phys. Hist. Nat. Genéve 1841, 9, 261-288.

30. Engelmann, G. Systematic arrangement of the species of the genus Cuscuta with critical remarks on old species and descriptions of new ones. Trans. Acad. Sci. Saint Louis 1859, 1, 453-523.

31. Peter, A. Convolvulaceae. In Die Natürlichen Pflanzenfamilien; Engler, A., Prantl, K., Eds.; W. Engelmann: Leipzig, Germany, 1897.

32. Mirande, M. Recherches Physiologiques et Anatomiques sur les Cuscutacées. Ph.D. Thesis, Faculté des Sciences de Paris, Paris, France, 1900.

33. Hunziker, A.T. Las especies de Cuscuta (Convolvulaceae) de Argentina y Uruguay. Revista de la Facultad de Ciencias Exactas Fisicas y Naturales; Impr. de la Universidad: Córdoba, Argentina, 1950; pp. 1101-1202.

34. Yuncker, T.G. Cuscuta. In North American Flora II. Part 4; New York Botanical Garden, Ed.; The New York Botanical Garden Press: New York, NY, USA, 1965; pp. 1-51.

35. Wright, M.A.; Ianni, M.D.; Costea, M. Diversity and evolution of pollen-ovule production in Cuscuta (dodders, Convolvulaceae) in relation to floral morphology. Plant Syst. Evol. 2012, 298, 369-389. [CrossRef]

36. García, M.A.; Costea, M.; Kuzmina, M.; Stefanović, S. Phylogeny, character evolution, and biogeography of Cuscuta (dodders; Convolvulaceae) inferred from coding plastid and nuclear sequences. Am. J. Bot. 2014, 101, 670-690. [CrossRef] [PubMed]

37. Abdel Khalik, K.N. Seed morphology of Cuscuta L. (Convolvulaceae) in Egypt and its systematic significance. Feddes Repert. 2006, 117, 217-224. [CrossRef]

38. Wang, Y.; Zhan, D.F.; Jia, X.; Mei, W.L.; Dai, H.F.; Chen, X.T.; Peng, S.Q. Complete chloroplast genome sequence of Aquilaria sinensis (Lour.) Gilg and evolution analysis within the Malvales order. Front. Plant Sci. 2016, 7, 280. [CrossRef]

39. Wolfe, K.H.; Morden, C.W.; Palmer, J.D. Function and evolution of a minimal plastid genome from a nonphotosynthetic parasitic plant. Proc. Natl. Acad. Sci. USA. 1992, 89, 10648-10652. [CrossRef]

40. Kim, H.T.; Kim, J.S.; Moore, M.J.; Neubig, K.M.; Williams, N.H.; Whitten, W.M.; Kim, J.H. Seven new complete plastome sequences reveal rampant independent loss of the $n d h$ gene family across Orchids and associated instability of the inverted repeat/small single-copy region boundaries. PLOS ONE 2015, 10, e0142215. [CrossRef]

41. Wicke, S.; Muller, K.F.; dePamphilis, C.W.; Quandt, D.; Bellot, S.; Schneeweiss, G.M. Mechanistic model of evolutionary rate variation en route to a nonphotosynthetic lifestyle in plants. Proc. Natl. Acad. Sci. USA 2016, 113, 9045-9050. [CrossRef] [PubMed]

42. Ni, Z.; Ye, Y.; Bai, T.; Xu, M.; Xu, L.A. Complete chloroplast genome of Pinus massoniana (Pinaceae): Gene rearrangements, loss of ndh genes, and short inverted repeats contraction, expansion. Molecules 2017, 22. [CrossRef] [PubMed]

43. Powell, W.; Morgante, M.; McDevitt, R.; Vendramin, G.G.; Rafalski, J.A. Polymorphic simple sequence repeat regions in chloroplast genomes: Applications to the population genetics of pines. Proc. Natl. Acad. Sci. USA 1995, 92, 7759-7763. [CrossRef] [PubMed]

44. Dong, W.; Xu, C.; Cheng, T.; Lin, K.; Zhou, S. Sequencing angiosperm plastid genomes made easy: A complete set of universal primers and a case study on the phylogeny of Saxifragales. Genome Biol. Evol. 2013, 5, 989-997. [CrossRef] [PubMed] 
45. Nie, X.; Lv, S.; Zhang, Y.; Du, X.; Wang, L.; Biradar, S.S.; Tan, X.; Wan, F.; Weining, S. Complete chloroplast genome sequence of a major invasive species, crofton weed (Ageratina adenophora). PLoS ONE 2012, 7, e36869. [CrossRef] [PubMed]

46. Khakhlova, O.; Bock, R. Elimination of deleterious mutations in plastid genomes by gene conversion. Plant J. 2006, 46, 85-94. [CrossRef]

47. Hansen, D.R.; Dastidar, S.G.; Cai, Z.; Penaflor, C.; Kuehl, J.V.; Boore, J.L.; Jansen, R.K. Phylogenetic and evolutionary implications of complete chloroplast genome sequences of four early-diverging angiosperms: Buxus (Buxaceae), Chloranthus (Chloranthaceae), Dioscorea (Dioscoreaceae), and Illicium (Schisandraceae). Mol. Phylogenet. Evol. 2007, 45, 547-563. [CrossRef] [PubMed]

48. Huang, H.; Shi, C.; Liu, Y.; Mao, S.Y.; Gao, L.Z. Thirteen Camellia chloroplast genome sequences determined by high-throughput sequencing: Genome structure and phylogenetic relationships. BMC Evol. Biol. 2014, 14, 151. [CrossRef] [PubMed]

49. Braukmann, T.; Kuzmina, M.; Stefanovic, S. Plastid genome evolution across the genus Cuscuta (Convolvulaceae): Two clades within subgenus Grammica exhibit extensive gene loss. J. Exp. Bot. 2013, 64, 977-989. [CrossRef]

50. Moore, M.J.; Bell, C.D.; Soltis, P.S.; Soltis, D.E. Using plastid genome-scale data to resolve enigmatic relationships among basal angiosperms. Proc. Natl. Acad. Sci. USA 2007, 104, 19363-19368. [CrossRef]

51. The Angiosperm Phylogeny Group; Chase, M.W.; Christenhusz, M.J.M.; Fay, M.F.; Byng, J.W.; Judd, W.S.; Soltis, D.E.; Mabberley, D.J.; Sennikov, A.N.; Soltis, P.S.; et al. An update of the Angiosperm Phylogeny Group classification for the orders and families of flowering plants: APG IV. Bot. J. Linn. Soc. 2016, 181, 1-20.

52. Bell, C.D.; Edwards, E.J.; Kim, S.-T.; Donoghue, M.J. Dipsacales phylogeny based on chloroplast DNA sequences. Harv. Pap. Bot. 2001, 6, 481-499.

53. Song, J.-H.; Moon, B.C.; Choi, G.; Yang, S. Morphological identification of Lepidii Seu Descurainiae Semen and adulterant seeds using microscopic analysis. Appl. Sci. 2018, 8, 2134. [CrossRef]

54. Delcher, A.L.; Salzberg, S.L.; Phillippy, A.M. Using MUMmer to identify similar regions in large sequence sets. Curr. Protoc. Bioinform. 2003, 1, 10.3.1-10.3.18. [CrossRef] [PubMed]

55. Luo, R.; Liu, B.; Xie, Y.; Li, Z.; Huang, W.; Yuan, J.; He, G.; Chen, Y.; Pan, Q.; Liu, Y.; et al. SOAPdenovo2: An empirically improved memory-efficient short-read de novo assembler. Gigascience 2012, 1, 18. [CrossRef]

56. Li, H.; Durbin, R. Fast and accurate long-read alignment with Burrows-Wheeler transform. Bioinformatics 2010, 26, 589-595. [CrossRef] [PubMed]

57. Wyman, S.K.; Jansen, R.K.; Boore, J.L. Automatic annotation of organellar genomes with DOGMA. Bioinformatics 2004, 20, 3252-3255. [CrossRef] [PubMed]

58. Lowe, T.M.; Eddy, S.R. tRNAscan-SE: A program for improved detection of transfer RNA genes in genomic sequence. Nucleic Acids Res. 1997, 25, 955-964. [CrossRef]

59. Lohse, M.; Drechsel, O.; Bock, R. OrganellarGenomeDRAW (OGDRAW): A tool for the easy generation of high-quality custom graphical maps of plastid and mitochondrial genomes. Curr. Genet. 2007, 52, $267-274$. [CrossRef]

60. Tamura, K.; Stecher, G.; Peterson, D.; Filipski, A.; Kumar, S. MEGA6: Molecular Evolutionary Genetics Analysis version 6.0. Mol. Biol. Evol. 2013, 30, 2725-2729. [CrossRef]

61. Darling, A.E.; Mau, B.; Perna, N.T. progressiveMauve: Multiple genome alignment with gene gain, loss and rearrangement. PLoS ONE 2010, 5, e11147. [CrossRef] [PubMed]

62. Yang, Z. PAML 4: Phylogenetic analysis by maximum likelihood. Mol. Biol. Evol. 2007, 24, $1586-1591$. [CrossRef] [PubMed]

63. Thiel, T. MISA-Microsatellite identification tool. 2003. Available online: Websitehttp://misaweb.ipkgatersleben.de/. (accessed on 2 March 2019).

64. Benson, G. Tandem repeats finder: A program to analyze DNA sequences. Nucleic Acids Res. 1999, 27, 573-580. [CrossRef]

65. Warburton, P.E.; Giordano, J.; Cheung, F.; Gelfand, Y.; Benson, G. Inverted repeat structure of the human genome: The X-chromosome contains a preponderance of large, highly homologous inverted repeats that contain testes genes. Genome Res. 2004, 14, 1861-1869. [CrossRef]

66. Katoh, K.; Misawa, K.; Kuma, K.I.; Miyata, T. MAFFT: A novel method for rapid multiple sequence alignment based on fast Fourier transform. Nucleic Acids Res. 2002, 30, 3059-3066. [CrossRef] [PubMed] 
67. Hall, T.A. BioEdit: A user-friendly biological sequence alignment editor and analysis program for Windows 95/98/NT. Nucleic Acid Symp. Ser. 1999, 41, 95-98.

68. Darriba, D.; Taboada, G.L.; Doallo, R.; Posada, D. jModelTest 2: More models, new heuristics and parallel computing. Nat. Methods 2012, 9, 772. [CrossRef] [PubMed]

69. Ronquist, F.; Teslenko, M.; van der Mark, P.; Ayres, D.L.; Darling, A.; Hohna, S.; Larget, B.; Liu, L.; Suchard, M.A.; Huelsenbeck, J.P. MrBayes 3.2: Efficient Bayesian phylogenetic inference and model choice across a large model space. Syst. Biol. 2012, 61, 539-542. [CrossRef]

Sample Availability: Samples of Cuscuta japonica and C. chinensis are available from the authors and the herbarium of KIOM.

(C) 2019 by the authors. Licensee MDPI, Basel, Switzerland. This article is an open access article distributed under the terms and conditions of the Creative Commons Attribution (CC BY) license (http://creativecommons.org/licenses/by/4.0/). 